Original Article (short paper)

\title{
Sports practice from childhood to adolescence: behavior patterns and associated factors
}

\author{
Heloyse Elaine Gimenes Nunes ${ }^{1}$, Diego Augusto Santos Silva² ${ }^{\circledR 0}$ \\ ${ }^{1}$ Universidade Federal do Mato Grosso do Sul, UFMS, Integrated Health Institute, Campo Grande, MS, Brazil; \\ ${ }^{2}$ Universidade Federal de Santa Catarina, UFSC, Department of Physical Education, Florianópolis, SC, Brazil
}

\begin{abstract}
Aim: To analyze the prevalence of sports practice patterns from childhood to adolescence, and to verify the association between sports practice and demographic factors (sex, age, and skin color), economic factors (maternal education and economic level) and current affinity for physical activities. Methods: A cross-sectional study was carried out with 1,112 adolescents (14-19 years) from southern Brazil. Sports practice patterns were composed of four combinations of sports practice from childhood to adolescence: (1) Practiced in both childhood and in adolescence; (2) Practiced in childhood but not in adolescence; (3) Did not practice in childhood but practices in adolescence; (4) Practice neither childhood nor in adolescence. Demographic, economic variables and current affinity for physical activities were evaluated by questionnaire. Multinomial logistic regression was used. Results: Of adolescents who practiced sports in childhood, $45.8 \%$ maintained the practice during adolescence (higher prevalence in males) and $14.1 \%$ gave up (higher prevalence in females). Of adolescents who did not practice sports in childhood, $27.6 \%$ started during adolescence (higher prevalence in males) and $12.5 \%$ maintained their childhood behavior (higher prevalence in females). Adolescents with low economic status who did not practice sports were more likely of not practicing this in both periods. Those who reported not enjoying physical activities were more likely of giving up sports in adolescence. Conclusion: Economic level and affinity for physical activities during adolescence are associated with sports practice patterns. Skin color, age, and maternal schooling are not associated with sports practice.
\end{abstract}

Keywords: physical activity, sport, health behavior, youth sports, sport psychology.

\section{Introduction}

Sport is considered as one of the ways to practice physical activity and guarantee health benefits from the early stages of life $\mathrm{e}^{1,2}$. The practice of sports since childhood influences the formation of psychosocial behavior, school performance, improvement of systemic functions and the formation of physical activity habits in later stages of life $\mathrm{e}^{1,2,3,4}$. However, studies suggest that there is a tendency to abandon sports practice with increasing age $e^{5,6,7}$.

Data that analyzed sports practice patterns in adolescents have indicated that approximately four out of 10 young people maintained their sports habits from childhood ${ }^{7,8}$. The abandon of sports practice varied from $10.0 \%$ to $20.4 \% 0^{7,9}$. To understand the behavioral trend during the period, other behavioral patterns such as starting practice during adolescence or not having practiced in both periods were included in some studies ${ }^{7,9}$.

Some factors seem to influence sports practice patterns from childhood to adolescence, such as demographic, economic factors, and those related to the affinity for physical activities ${ }^{6,7,10}$. Studies have shown that boys, younger children, white individuals, those with higher economic level and mothers with higher schooling tend to have a greater chance of maintaining sports habit ${ }^{7,11}$. The affinity for physical activities seems to determine the maintenance or abandonment of sports practice in young people, and there is a relationship between practice sport during childhood and the formation of affinity for physical activities during adolescence ${ }^{7,12,13,14}$.

In this sense, this study is justified: (a) to reduce the prevalence of sports practice abandonment during adolescence and of individuals who did not practice sports in both periods (childhood and adolescence) from the identification of factors associated with this patterns ${ }^{15}$; (b) due to the scarcity of studies that evaluated demographic and economic factors, and these factors are considered as potential confounders for sports practice ${ }^{16}$; (c) the inclusion of demographic and economic factors together with intrapersonal aspects (such as affinity for physical activities) to help in the understanding the interrelationship of different factors associated with sports practice ${ }^{17} ;$ (d) to understand cultural differences about sports practice in Brazilian adolescents ${ }^{6}$; (e) the importance of sports practice in children and adolescents to improve physical fitness, learning sport-specific skills and as a predictor of adulthood physical activity ${ }^{1,3,7}$. Therefore, the aim of the present study was to analyze the prevalence of sports practice patterns from childhood to adolescence and to verify the association between sports practice and demographics (sex, age, and skin color), and economic factors (maternal schooling and economic level) and the current affinity for physical activities. 


\section{Methods}

The present study is considered a descriptive epidemiological study with cross-sectional design and was approved by the Human Research Ethics Committee of the Federal University of Santa Catarina (UFSC) (CAAE protocol: 33210414.3.0000.0121) as part of the macro project entitled "Brazilian Guide for Assessment of Physical Fitness Related to Health and Life Habits".

The population was composed of 5,182 high school students (distributed in 11 eligible schools and 170 classes) aged 14-19 years enrolled in public high schools in the city of São José, Santa Catarina, Brazil. The sampling process was determined in two stages: 1) stratified by public high schools; 2) clusters of classes considering shift and grade (at this stage, all high school students who were in the classroom on the days of data collection were invited to participate in the research). The total sample was 1,112 students (seven schools were collected). Data on estimates for the calculation of the sampling process (inclusion, exclusion criteria and eligibility) can be found in literature ${ }^{18}$.

The instruments were pre-tested and at the beginning of the second semester, the pilot study was carried out (July 2014). Data collection was performed from August to November 2014. The research team was composed of undergraduate and graduate students previously familiar and trained to apply the questionnaires and physical assessments. All students signed the Assent Form and parents/guardians the Informed Consent Form.

\section{Dependent variable}

Sports practice patterns were composed of possible combinations of sports practice in childhood (considering the period from 7 to 10 years) and adolescence, forming categories "practiced in childhood but not in adolescence", "did not practice in childhood but practices in adolescence", "neither practice in childhood nor in adolescence" and "practiced in both childhood and adolescence".

The sports practice in childhood was considered when performed under the supervision of the teacher, with at least six months without interruption, and that did not include school Physical Education. And sports practice in adolescence was obtained by adolescents' response to the frequency and duration of sports practiced at the time of the research (at least one month), considering the minimum frequency of once weekly and the possibility of adolescents practicing more than one sport simultaneously.

\section{Independent variables}

A self-administered questionnaire was used to assess demographic variables (sex, age, and skin color) and economic variables (study shift, economic level and maternal schooling). Sex (female and male), skin color (white, brown, black, yellow and indigenous) and study shift (day and night) were self-reported. The skin color categories were collected according to recommendations of the Brazilian Institute of Geography and Statistics ${ }^{19}$. However, for the analysis of data, brown, black, yellow and indigenous categories were grouped into a single category ${ }^{20}$.

Age was continuously collected and dichotomized into 14-16 years and 17-19 years to ensure homogeneous distribution of frequency in each category. The economic level was evaluated by the purchasing power of families, and classified into five categories: "A", "B", "C", "D" and "E", in descending order ${ }^{21}$. For the present study, categories " $A$ " and "B" were defined as "high" and the others as "low". Maternal schooling was collected by questioning until which school grade the mother studied, being classified in schooling $<8$ years of study and schooling $\geq 8$ years of study.

To assess the current affinity for physical activities, the following question was made: "I like to do physical activities. What would you say about this statement?", considering "yes" those who indicated "totally agree", "partially agree" and "no", those that marked "neither agree nor disagree","disagree in part" and "totally disagree". This question is part of the Global School-based Student Health Survey, which has been translated and validated for Brazilian adolescents ${ }^{22}$.

\section{Statistical analysis}

The chi-square test of heterogeneity and the linear tendency was used to evaluate differences between groups for each sports practice pattern. Associations between the dependent variable (sports practice patterns in childhood and adolescence) and independent variables were analyzed by multinomial logistic regression, with an odds ratio (OR) and their respective confidence intervals $(95 \% \mathrm{CI})$. The reference category used was "practiced in childhood and in adolescence", that is, the maintenance of sports practice in this period. For regression analysis, the adjustment was performed by all independent variables using the backward method $(\mathrm{p}<0.20)$. For all analyses, a significance level of $5 \%$ was adopted. Analyses were stratified by sex and the Statistical Package for Social Sciences (SPSS) 22.0 software (Chicago, USA) was used.

\section{Results}

The sample consisted of 1,120 adolescents with a mean age of $16.1 \pm 1.1$ years. The prevalence of adolescents who practiced sports during childhood was $59.7 \%$ and adolescents practicing sports were $73.2 \%$. Higher prevalence of adolescents who maintained sports practice from childhood to adolescence was observed in males, in those who had mothers with higher schooling, high economic level and who enjoyed sports practice (both in childhood and adolescence). Higher prevalence of young individuals who practiced sports during childhood, but gave up during adolescence, was 
observed in females, in those who had mothers with high schooling, high economic level, who were forced to practice sport in childhood and who reported not enjoying physical activities. Higher prevalence of adolescents who did not practice sports in childhood but who began to practice in adolescence was observed in males, who had mothers with low educational level, low economic level and who reported enjoying physical activities. Higher prevalence of adolescents who did not practice sports in both periods (childhood and adolescence) was observed in females, who had mothers with low educational level, low economic level and who reported not enjoying physical activities (Table 1).

Table 1. Previous and current sports practice of adolescents according to demographic, economic variables and affinity for physical activities.

\begin{tabular}{|c|c|c|c|c|c|c|c|c|c|c|c|c|}
\hline \multirow[t]{2}{*}{ Variables } & \multicolumn{2}{|c|}{$\begin{array}{l}\text { Practiced } \\
\text { sports in } \\
\text { childhood }\end{array}$} & \multicolumn{2}{|c|}{$\begin{array}{c}\text { Practice } \\
\text { sports in } \\
\text { adolescence }\end{array}$} & \multicolumn{2}{|c|}{$\begin{array}{l}\text { Practiced in } \\
\text { childhood / } \\
\text { Practices in } \\
\text { adolescence }\end{array}$} & \multicolumn{2}{|c|}{$\begin{array}{l}\text { Practiced in } \\
\text { childhood / } \\
\text { Does not } \\
\text { practice in } \\
\text { adolescence }\end{array}$} & \multicolumn{2}{|c|}{$\begin{array}{l}\text { Did not } \\
\text { practice in } \\
\text { childhood / } \\
\text { practices in } \\
\text { adolescence }\end{array}$} & \multicolumn{2}{|c|}{$\begin{array}{l}\text { Did not } \\
\text { practice in } \\
\text { childhood / } \\
\text { Does not } \\
\text { practice in } \\
\text { adolescence }\end{array}$} \\
\hline & n & $(\%)$ & $\mathbf{n}$ & $(\%)$ & $\mathbf{n}$ & $(\%)$ & n & $(\%)$ & n & $(\%)$ & $\mathbf{n}$ & $(\%)$ \\
\hline Total $(n=1112)$ & 669 & $(60.1)$ & 820 & $(73.7)$ & 509 & $(45.8)$ & 157 & $(14.1)$ & 307 & $(27.6)$ & 139 & (12.5) \\
\hline $\operatorname{Sex}(n=1112)$ & \multicolumn{2}{|c|}{$p=0.045^{\mathrm{a}}$} & \multicolumn{2}{|c|}{$p<0.001^{\mathrm{a}}$} & \multicolumn{2}{|c|}{$p<0.001^{\mathrm{a}}$} & \multicolumn{2}{|c|}{$p<0.001^{\mathrm{a}}$} & \multicolumn{2}{|c|}{$p<0.001^{\mathrm{a}}$} & \multicolumn{2}{|c|}{$p<0.001^{\mathrm{a}}$} \\
\hline Female & 348 & $(57.0)$ & 383 & $(63.1)$ & 229 & $(37.8)$ & 117 & $(19.3)$ & 156 & $(25.7)$ & 104 & $(17.2)$ \\
\hline Male & 321 & $(62.9)$ & 437 & $(85.2)$ & 280 & $(55.3)$ & 40 & $(7.9)$ & 151 & $(29.8)$ & 35 & $(6.9)$ \\
\hline Age $(n=1112)$ & \multicolumn{2}{|c|}{$p=0.371^{\mathrm{b}}$} & \multicolumn{2}{|c|}{$p=0.557^{\mathrm{b}}$} & \multicolumn{2}{|c|}{$p=0.493^{\mathrm{b}}$} & \multicolumn{2}{|c|}{$p=0.493^{\mathrm{b}}$} & \multicolumn{2}{|c|}{$p=0.493^{\mathrm{b}}$} & \multicolumn{2}{|c|}{$p=0.493^{\mathrm{b}}$} \\
\hline $14-16$ years & 393 & $(58.7)$ & 497 & $(73.8)$ & 290 & $(43.6)$ & 101 & $(15.1)$ & 204 & $(30.6)$ & 72 & $(10.8)$ \\
\hline $17-19$ years & 276 & $(61.3)$ & 323 & $(72.3)$ & 219 & $(49.2)$ & 56 & $(12.6)$ & 103 & $(23.1)$ & 67 & $(15.1)$ \\
\hline Skin color $(\mathrm{n}=1108)$ & \multicolumn{2}{|c|}{$p=0.515^{\mathrm{a}}$} & \multicolumn{2}{|c|}{$p=0.802^{\mathrm{a}}$} & \multicolumn{2}{|c|}{$p=0.854^{\mathrm{a}}$} & \multicolumn{2}{|c|}{$p=0.854^{\mathrm{a}}$} & \multicolumn{2}{|c|}{$p=0.854^{\mathrm{a}}$} & \multicolumn{2}{|c|}{$p=0.854^{\mathrm{a}}$} \\
\hline White & 406 & $(58.9)$ & 497 & $(72.7)$ & 307 & $(44.9)$ & 96 & $(14.0)$ & 191 & $(27.9)$ & 90 & $(13.2)$ \\
\hline Others & 257 & $(60.9)$ & 311 & $(73.3)$ & 196 & $(46.8)$ & 61 & $(14.6)$ & 113 & $(27.0)$ & 49 & $(11.7)$ \\
\hline Study shift (n=1112) & \multicolumn{2}{|c|}{$p=0.949^{\mathrm{a}}$} & \multicolumn{2}{|c|}{$p=0.829^{\mathrm{a}}$} & \multicolumn{2}{|c|}{$p=0.851^{\mathrm{a}}$} & \multicolumn{2}{|c|}{$p=0.851^{\mathrm{a}}$} & $p=0$ & $851^{\mathrm{a}}$ & $p=0$ & $851^{\mathrm{a}}$ \\
\hline Day & 488 & $(59.6)$ & 598 & $(73.3)$ & 369 & $(45.4)$ & 117 & $(14.4)$ & 228 & $(28.0)$ & 99 & $(12.2)$ \\
\hline Night & 177 & $(59.8)$ & 215 & $(72.6)$ & 137 & $(46.6)$ & 39 & $(13.3)$ & 78 & $(26.5)$ & 40 & (13.6) \\
\hline Maternal schooling $(\mathrm{n}=1107)$ & $p=0$ & $011^{\mathrm{b}}$ & $p=($ & $176^{\mathrm{b}}$ & $p=($ & $006^{\mathrm{b}}$ & $p=0$ & $006^{\mathrm{b}}$ & $p=0$ & $006^{\mathrm{b}}$ & $p=0$ & $006^{\mathrm{b}}$ \\
\hline$\geq 8$ years & 469 & $(62.2)$ & 559 & $(74.1)$ & 358 & $(47.7)$ & 110 & $(14.7)$ & 199 & $(26.5)$ & 83 & (11.1) \\
\hline$<8$ years & 193 & $(54.2)$ & 248 & $(70.3)$ & 144 & $(40.9)$ & 47 & $(13.4)$ & 105 & $(29.8)$ & 56 & $(15.9)$ \\
\hline Economic level ( $\mathrm{n}=952)$ & $p=0$ & $003^{\mathrm{b}}$ & $p=($ & $012^{\mathrm{b}}$ & $p<0$ & $001^{\mathrm{b}}$ & $p<0$ & $001^{\mathrm{b}}$ & $p<0$ & $001^{\mathrm{b}}$ & $p<0$ & $001^{\mathrm{b}}$ \\
\hline High & 416 & $(62.9)$ & 489 & $(74.0)$ & 311 & $(47.3)$ & 104 & $(15.8)$ & 176 & $(26.7)$ & 67 & $(10.2)$ \\
\hline Low & 153 & $(52.6)$ & 192 & $(66.0)$ & 113 & $(39.0)$ & 39 & $(13.4)$ & 81 & $(27.9)$ & 57 & $(19.7)$ \\
\hline Reason for practice in childhood $(\mathrm{n}=741)$ & $p=0$ & $040^{\mathrm{a}}$ & $p=($ & $540^{\mathrm{a}}$ & $p<1$ & $011^{\mathrm{a}}$ & $p<0$ & $011^{\mathrm{a}}$ & & Not ap & lied* & \\
\hline Affinity for sports & 636 & $(88,7)$ & 546 & $(76,3)$ & 487 & $(68,3)$ & 146 & $(20,5)$ & & Not. & & \\
\hline Was forced & 18 & $(75,0)$ & 17 & $(70,8)$ & 11 & $(45,8)$ & 7 & $(29,2)$ & & vol ap & Hed & \\
\hline Current affinity for physical activities $(\mathrm{n}=1102)$ & $p=0$ & $019^{\mathrm{a}}$ & $p<$ & $001^{\mathrm{a}}$ & $p<0$ & $001^{\mathrm{a}}$ & $p<0$ & $001^{\mathrm{a}}$ & $p<0$ & $001^{\mathrm{a}}$ & $p<0$ & $001^{\mathrm{a}}$ \\
\hline Yes & 553 & $(61,4)$ & 712 & $(79,0)$ & 450 & $(50,2)$ & 100 & $(11,1)$ & 261 & 29,1 & 86 & 9,6 \\
\hline No & 106 & $(52,5)$ & 94 & $(47,5)$ & 53 & $(26,8)$ & 53 & $(26,8)$ & 42 & 21,2 & 50 & 25,3 \\
\hline
\end{tabular}

${ }^{a}$ Chi-square test of heterogeneity, ${ }^{b}$ Chi-square test of linear trend, * These subjects did not practice sport in childhood; OR, Odds Ratio; CI, Confidence Interval.

${ }^{a}$ Reference category: Maintenance of sports practice from childhood to adolescence.

${ }^{\mathrm{b}}$ Analysis adjusted by all independent variables.

In males, it was observed that adolescents who did not enjoy (at the time of the research) physical activities were more likely of giving up sports practice in adolescence than those who maintained sports practice from childhood to adolescence $(\mathrm{OR}=4.02)$. Adolescents with low economic level and who did not enjoy (at the time of research) physical activities were more likely of not practicing sports during childhood and adolescence than those who maintained practice during the entire period $(\mathrm{OR}=3.14$ and $\mathrm{OR}=9.55$, respectively) (Table 2 ). 
Table 2. Factors associated with sports practice in the period from childhood to adolescence in male students from São José / SC, Brazil

\begin{tabular}{|c|c|c|c|c|c|c|}
\hline \multirow[b]{2}{*}{$\begin{array}{c}\text { Adjusted analysis } \\
\text { Variable }\end{array}$} & \multicolumn{2}{|c|}{$\begin{array}{c}\text { Practiced in childhood } / \\
\text { Does not practice in } \\
\text { adolescence }^{\mathrm{a}}\end{array}$} & \multicolumn{2}{|c|}{$\begin{array}{l}\text { Did not practice in childhood / } \\
\text { practices in adolescence }^{\mathrm{a}}\end{array}$} & \multicolumn{2}{|c|}{$\begin{array}{c}\text { Did not practice in childhood / } \\
\text { Does not practice in } \\
\text { adolescence }^{\mathrm{a}}\end{array}$} \\
\hline & OR (IC95\%) & p-value & OR (IC95\%) & p-value & OR (IC95\%) & p-value \\
\hline Age & & 0.52 & & 0.07 & & 0.21 \\
\hline 14-16 years & 1.00 & & 1.00 & & 1.00 & \\
\hline 17-19 years & $0.78(0.37-1.64)$ & & $0.66(0.42-1.03)$ & & $1.68(0.74-3.79)$ & \\
\hline Skin color & & 0.76 & & 0.61 & & 0.15 \\
\hline White & 1.00 & & 1.00 & & 1.00 & \\
\hline Others & $0.89(0.41-1.92)$ & & $0.88(0.55-1.42)$ & & $0.51(0.20-1.27)$ & \\
\hline Maternal schooling & & 0.82 & & 0.63 & & 0.07 \\
\hline$\geq 8$ years & 1.00 & & 1.00 & & 1.00 & \\
\hline$<8$ years & $1.10(0.46-2.61)$ & & $1.13(0.68-1.87)$ & & $2.24(0.91-5.48)$ & \\
\hline Economic level & & 0.96 & & 0.36 & & $<0.01$ \\
\hline High & 1.00 & & 1.00 & & 1.00 & \\
\hline Low & $1.02(0.43-2.41)$ & & $1.26(0.76-2.07)$ & & $3.14(1.38-7.12)$ & \\
\hline Study shift & & 0.51 & & 0.09 & & 0.83 \\
\hline Day & 1.00 & & 1.00 & & 1.00 & \\
\hline Night & $0.72(0.27-1.91)$ & & $1.53(0.92-2.55)$ & & $0.90(0.35-2.34)$ & \\
\hline Affinity for physical activities & & $<0.01$ & & 0.64 & & $<0.01$ \\
\hline Yes & 1.00 & & 1.00 & & 1.00 & \\
\hline No & $4.02(1.74-9.27)$ & & $1.17(0.59-2.34)$ & & $9.55(4.10-22.2)$ & \\
\hline
\end{tabular}

OR, Odds Ratio; CI, Confidence Interval.

${ }^{\text {a }}$ Reference category: Maintenance of the sports practice of childhood during adolescence.

In females, adolescents who did not enjoy (at the time of research) physical activities were more likely of giving up their previous sports practice during adolescence when compared to those who maintained sports habit since childhood
$(\mathrm{OR}=3.72)$. Girls who were more likely of not playing sports in childhood and adolescence were those with lower economic level $(\mathrm{OR}=1.86)$ and who reported not enjoying physical activities $(\mathrm{OR}=3.66)($ Table 3$)$.

Table 3. Factors associated with sports practice in the period from childhood to adolescence in female students from São José / SC, Brazil

\begin{tabular}{|c|c|c|c|c|c|c|}
\hline \multirow[b]{2}{*}{$\begin{array}{l}\text { Adjusted analysis }^{\mathbf{b}} \\
\text { Variable }\end{array}$} & \multicolumn{2}{|c|}{$\begin{array}{c}\text { Practiced in childhood/ } \\
\text { Does not practice in adolescence }\end{array}$} & \multicolumn{2}{|c|}{$\begin{array}{c}\text { Did not practice in childhood/ } \\
\text { practices in adolescence }\end{array}$} & \multicolumn{2}{|c|}{$\begin{array}{l}\text { Did not practice in childhood/ } \\
\text { Does not practice in adolescence }\end{array}$} \\
\hline & OR (IC95\%) & p-value & OR (IC95\%) & p-value & OR (IC95\%) & p-value \\
\hline Age & & 0.18 & & 0.16 & & 0.28 \\
\hline 14-16 years & 1,00 & & 1.00 & & 1.00 & \\
\hline 17-19 years & $0,70(0,42-1,17)$ & & $0.71(0.44-1.15)$ & & $1.32(0.78-2.23)$ & \\
\hline Skin color & & 0.82 & & 0.90 & & 0.49 \\
\hline White & 1,00 & & 1.00 & & 1.00 & \\
\hline Others & $0,94(0,57-1,56)$ & & $0.97(0.61-1.54)$ & & $0.83(0.48-1.41)$ & \\
\hline Maternal schooling & & 0.98 & & 0.09 & & 0.10 \\
\hline$\geq 8$ years & 1,00 & & 1.00 & & 1.00 & \\
\hline$<8$ years & $0,99(0,57-1,72)$ & & $1.50(0.92-2.45)$ & & $1.57(0.91-2.71)$ & \\
\hline Economic level & & 0.93 & & 0.57 & & 0.02 \\
\hline High & 1,00 & & 1.00 & & 1.00 & \\
\hline Low & $1,02(0,59-1,75)$ & & $1.15(0.70-1.87)$ & & $1.86(1.08-3.18)$ & \\
\hline Study shift & & 0.98 & & 0.09 & & 0.87 \\
\hline Day & 1,00 & & 1.00 & & 1.00 & \\
\hline Night & $1,01(0,57-1,77)$ & & $0.62(0.36-1.09)$ & & $0.95(0.53-1.71)$ & \\
\hline Affinity for physical activities & & $<0,01$ & & 0.48 & & $<0.01$ \\
\hline Yes & 1,00 & & 1.00 & & 1.00 & \\
\hline No & $3,72(2,03-6,80)$ & & $1.26(0.65-2.46)$ & & $3.66(1.93-6.91)$ & \\
\hline
\end{tabular}

${ }^{\mathrm{b}}$ Analysis adjusted by all independent variables. 
The most sport performed of adolescents who maintained sports practice from childhood to adolescence was soccer $(47.9 \%)$.

\section{Discussion}

Of adolescents who practiced sports in childhood, $45.8 \%$ maintained sports during adolescence and $14.1 \%$ gave up. Of adolescents who did not practice sports in childhood, $27.6 \%$ started during adolescence and $12.5 \%$ maintained their childhood behavior. Low economic level adolescents were more likely of not practicing sports from childhood to adolescence compared to those who maintained sports during this period (in both sexes). Adolescents who reported not enjoying physical activities were more likely of giving up sports in adolescence and also were more likely of not having practiced sports either in childhood or adolescence when compared to those who maintained practice (in both sexes).

The maintenance of physical activity during the course of life has been investigated in other studies ${ }^{2,4,7,8}$. A cohort study conducted in Pelotas, Brazil, with 3,736 adolescents (18 years) found that $48.5 \%$ of these adolescents maintained themselves physically active since childhood (11 years $)^{8}$. Another study reported that subjects engaged in sports activities during both periods (childhood and adolescence) were $82 \%$ less likely to report dyslipidemia in adult life, lower low-density lipoprotein and carotid intima-media thickness values ${ }^{4}$. In addition, maintaining physical activity practice in young people (children and adolescents) increases the likelihood of remaining active in adult life $^{2}$. One of the justifications for this fact is that previous physical activity may modify internal control factors (such as self-efficacy and physical activity skills) and external control factors (with the opportunities and constraints when performing physical activities) in the later stages of life $\mathrm{e}^{7,14,23,24}$.

The prevalence of sports practice maintenance $(45.8 \%)$ was higher than the prevalence of dropout (14.1\%), as observed in a cohort study conducted in Germany $(48.5 \%$ maintained the practice and $20.5 \%$ gave up during adolescence $)^{7}$. Factors such as low level of physical fitness, lack of time (due to increased study load and the need to work) and personal factors (lack of pleasure, perception of competence, social pressures, and priorities) may have conditioned these adolescents to give up sports ${ }^{7,12,14,15}$. These factors demonstrate the need for previous experience with the sports (during childhood) to be pleasurable, motivating, diversified and inclusive (aspects found in sports for educational purposes) mainly within the school ${ }^{26,27}$. In this perspective, the role of the physical education teacher (in the planning of classes and the concern to promote student participation) is fundamental to reduce sports practice abandonment and maintain the benefits acquired during childhood ${ }^{4,14,25,27}$. Otherwise, individuals who would most need to maintain themselves in sporting practices (due to their low levels of physical fitness, negative psychological aspects, and poor motor skills) will be the most likely to give up sport practice ${ }^{7,26}$.

In the present study, of adolescents who did not practice sports in childhood, $27.6 \%$ started during adolescence and
$12.5 \%$ maintained their childhood behavior. Studies conducted in Germany and Australia, respectively, the observed prevalence of $12.3 \%$ and $10.0 \%$ for children who started sports practice during adolescence and, respectively, $18.7 \%$ and $12.0 \%$ for young people who did not practice sports in both periods ${ }^{7,9}$. Differences in prevalence may be justified by methodological aspects, as studies in Germany and Australia have evaluated the parents of individuals in the childhood period. In addition, there is a difference in the parameters used to consider regular sports practice and in the period between assessments (from childhood to adolescence $)^{7,9}$.

The low economic level demonstrated to negatively influence the sporting habit in the present study. Individuals with low economic status tend to have less participation in extracurricular activities (such as sports) ${ }^{28,29}$. Specific characteristics of this population such as cultural aspects (traditions and preferences), educational aspirations of mothers for their children, insufficient financial resources to invest in sports, lack of opportunity, school infrastructure and safety in public spaces, are factors that reduce adherence and maintenance of sports practice from childhood to adolescence in individuals of low economic level ${ }^{27,29}$.

The affinity for physical activities was considered a factor that interfered with the abandonment of sports practice and for not practicing sports in both periods (childhood and adolescence), as observed in other studies ${ }^{12,13}$. Affinity is related to affection, emotion, perception of competence, attitude, and cognition, being, therefore, a multidimensional construct ${ }^{30}$. Evidence has shown that previous experiences in a given behavior (such as sports practice) contribute to the construction of affinity for this behavior ${ }^{7,14,31}$. Lack of affinity, low self-esteem and low perception of competence were observed in children with low physical fitness since they presented difficulties in acquiring sports skills ${ }^{7,14}$. In turn, low physical fitness was a predictor of abandonment from physical activity in the six years following negative experience ${ }^{31}$.

Among the sports activities most practiced by adolescents who maintained practice since childhood, soccer was the most reported in the present study. A meta-analysis that analyzed the most common sports during childhood and adolescence in 47 countries presented divergent results according to the continental regions ${ }^{6}$. Soccer was considered the most popular among young people in the Americas and Europe (prevalence of 30.6\% and $29.0 \%$, respectively). In Africa, athletics was the most practiced sport (20.9\%), in the Eastern Mediterranean and the Western Pacific, swimming was the most popular $(32.0 \%$ and $17.7 \%$, respectively $)^{6}$. These data show that cultural and economic aspects can influence the maintenance of the practice of a given modality in young people ${ }^{6}$. Brazil has a strong culture related to soccer practice, and since childhood, soccer-related sports skills are stimulated, increasing the perception of competence and reducing practice abandonment ${ }^{14}$.

Sports practice during childhood has been retrospectively evaluated and can present memory bias, being therefore considered a study limitation. To minimize this bias, it was considered as a sports practice in childhood those individuals who practiced sports for at least six months without interruption. Future studies could include other important confounding 
factors (parent's previous and current physical activity). As a contribution of the present study, it is possible to emphasize that the factors associated with the practice of sports practice from childhood to adolescence were presented based on four possible patterns from childhood to adolescence (abandonment, maintenance, beginning of practice in adolescence, not practicing in both periods).

\section{Conclusions}

It could be concluded that adolescents who practiced sports in childhood, more than half maintained the practice in adolescence and about one-third gave up practicing sports. The economic level and the current affinity for physical activities were associated with sports practice from childhood to adolescence, and those with low economic level and who reported not enjoying physical activities were more likely of not practicing sports in both periods (childhood and adolescence). Those who reported not enjoying physical activities were more likely of giving up practicing sports during adolescence.

\section{Rerefences}

1. Koo JE, Lee KU. The relationships of elementary school students' sports participation with optimism, humor styles, and school life satisfaction. J Exerc Rehabil. 2014;10(2):111-7.

2. Lima MCS, Barbosa MF, Diniz TA, Codogno JS, Freitas Junior IF, Fernandes RA. Early and current physical activity: relationship with intima-media thickness and metabolic variables in adulthood. Braz J Phy Therapy. 2014;18(5):462-9.

3. Kjønniksen L, Anderssen N, Wold B. 2009 Organized youth sport as a predictor of physical activity in adulthood. Scand J Med Sci Sports. 2009; 19:646-54.

4. Fernandes RA, Sponton CHG, Zanesco A. Health-Promoting Effects of Early Physical Activity in Adulthood. Revista da SOCERJ. 2009;22: 365-372.

5. González-Gross M, Meléndez A. Sedentarism, active lifestyle and sport: Impact on health and obesity prevention. Nutr Hosp. 2013;28:89-98.

6. Hulteen RM, Smith JJ, Morgan PJ, Barnett LM, Hallal PC, Colyvas et al. Global participation in sport and leisure-time physical activities: A systematic review and meta-analysis. Prev Med. 2017; 95:14-25.

7. Manz K, Krug S, Schienkiewitz A, Finger JD. Determinants of organised sports participation patterns during the transition from childhood to adolescence in Germany: results of a nationwide cohort study. BMC Public Health. 2016;6:939.

8. Azevedo MR, Menezes AM, Assunção MC, Gonçalves H, Arumi I, Horta BL. et al. Tracking of physical activity during adolescence: the 1993 Pelotas Birth Cohort, Brazil. Rev Saúde Pública. 2014;48(6):925-30.

9. Vella SA, Cliff DP, Magee CA, Okely AD. Sports participation and parent-reported health-related quality of life in children: longitudinal associations. J Pediatr. 2014;164(6):1469-74.
10. Forthofer M, Dowda M, O’Neill JR, Addy CL, McDonald S, Reid L. et al. Effect of child gender and psychosocial factors on physical activity from fifth to sixth grade. J Phys Act Health. 2017;14(12): 953-958.

11. Dollman J, Lewis LR. The impact of socioeconomic position on sport participation among South Australian youth. J Sci Med Sport. 2010;13(3):318-32.

12. Martinez Baena AC, Chillón P, Martín-Matillas M, Pérez López I, Castilho R, Zapatera B et al. Motivos de abandono y no práctica de actividad físico-deportiva en adolescentes españoles: estudio Avena. CPD (online). 2012;12(1): 45-54.

13. Bacil EDA, Mazzardo Júnior O, Rech CR, Legnani RFS, Campos W. Physical activity and biological maturation: a systematic review. Rev PaulPediatr. 2015;33(1): 114-21.

14. Crane J, Temple V. A systematic review of dropout from organized sport among children and youth. Euro Phys Educ Rev. 2015;21:114-131.

15. Pate RR, Dowda M, O’Neill JR, Ward DS. Change in physical activity participation among adolescent girls from 8th to 12 th grade. J Phys Act Health. 2007;4: 3-16.

16. Balish SM, McLaren CM, Rainham D, Blanchard C. Correlates of youth sport attrition: A review and future directions. Psychol Sport Exerc. 2014;15(4):429-39.

17. Peugh JL. A practical guide to multilevel modeling. J Sch Psychol. 2010;48(1):85-112.

18. Silva DA, Tremblay M, Pelegrini A, Dos Santos Silva RJ, Cabral de Oliveira AC, Petroski EL. Association Between Aerobic Fitness and High Blood Pressure in Adolescents in Brazil: Evidence for Criterion-Referenced Cut-Points. Pediatr Exerc Sci. 2016;28(2): 12-20.

19. Brazilian Institute of Geography and Statistics. Censo Demográfico 2010. Ministério do Planejamento, Orçamento e Gestão. 2013. Accessed in: 4 Dec 2017. Available in: http://censo2010.ibge. gov.br/apps/atlas/.

20. World Health Organization. Handbook on health inequality monitoring: with a special focus on low- and middle-income countries. World Health Organization. 2013. Acessed in: 4 Dec 2017. Available in: http://www.who.int/gho/health_equity/handbook/en/.

21. Brazilian Association of Research Companies. Critério de Classificação Econômica Brasil. Associação Brasileira de Empresas de Pesquisa. 2014. Available in: http://www.abep.org/criterio-brasil. Acessed in: 4 Dec 2017.

22. Hardman CM, Barros SSH, Andrade MLSS, Nascimento JV, Nahas MV, Barros MVG. Participation in physical education classes and indicators of attitudes toward physical activity in adolescents. Rev Bras Educ Fís Esporte. 2013 ;27(4): 623-31.

23. Norman P, Conner M, Bell R. The Theory of Planned Behaviour and exercise: Evidence for the moderating role of past behavior. Br J Health Psychol. 2000;5:249-61.

24. Reverdito RS, Carvalho HM, Galatti LR, Scaglia AJ, Gonçalves CE, Paes RR. Effects of Youth Participation in Extra-Curricular Sport Programs on Perceived Self-Efficacy: A Multilevel Analysis. Percept Mot Skills. 2017;124(3): 569-83. https://doi. org/10.1177/0031512517697069.

25. Costa LCA, Nascimento JV, Vieira LF. Teaching invasive team sports in the school environment: from theory to practice from the perspective of a hybrid model. J Phys Educ. 2016;27: e2709. 
26. Fitzgerald H. Still feeling like a spare piece of luggage? Embodied experiences of (dis)ability in physical education and school sport. Phys Educ Sport Pedagogy. 2005;10(1): 41-59.

27. Yoo J. Perceived autonomy support and behavioral engagement in physical education: a conditional process model of positive emotion and autonomous motivation. Percept Mot Skills. 2015;120(3):731-46.

28. Dawes NP, Modecki KL, Gonzales N, Dumka L, Millsap R 2015 Mexican-Origin. Youth Participation in Extracurricular Activities: Predicting Trajectories of Involvement from 7th to 12th Grade. J Youth Adolescent 44: 2172-88.

29. Loptson K, Muhajarine N, Ridalls T, Smart Cities, Healthy Kids Research Team. Walkable for whom? Examining the role of the built environment on the neighbourhood-based physical activity of children. Can J Public Health. 2012;26(9): eS29-34.

30. Hashim H, Grove RJ, Whipp P. Validating the youth sport enjoyment construct in high school physical education. Res Q Exerc Sport. 2008;79(2):183-94.

31. Barnett LM, van Beurden E, Morgan PJ, Brooks LO, Beard JR. Childhood motor skill proficiency as a predictor of adolescent physical activity. J Adolesc Health. 2009;44(3): 252-9.

\section{Corresponding author}

Diego A S Silva

Departamento de Educação Física, Centro de Desportos, Universidade Federal de Santa Catarina, Campus Universitário - Trindade, Caixa Postal 476, 88040-900, Florianópolis, Santa Catarina, Brazil. Email: diegoaugustoss@yahoo.com.br

Manuscript received on January 14, 2019

Manuscript accepted on May 10, 2019

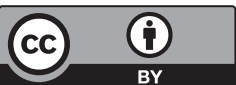

Motriz. The Journal of Physical Education. UNESP. Rio Claro, SP, Brazil - eISSN: 1980-6574 - under a license Creative Commons - Version 4.0 